\title{
Erratum to: Neighborhood aggregation effect and its effective scale on reproductive success in Shorea laxa (Dipterocarpaceae)
}

\author{
Yayoi Takeuchi $\cdot$ Hiromitsu Samejima \\ Michiko Nakagawa $\cdot$ Bibian Diway $\cdot$ \\ Tohru Nakashizuka
}

Published online: 16 December 2009

(C) The Botanical Society of Japan and Springer 2009

\section{Erratum to: J Plant Res}

\section{DOI 10.1007/s10265-009-0265-1}

In Fig. 1, the filled circles were incorrectly shown. The corrected figure appears below.

Fig. 1 Spatial distribution of Shorea laxa larger than $30 \mathrm{~cm}$ diameter at breast height (DBH). Filled circles focal trees, open circles potentially flowering trees

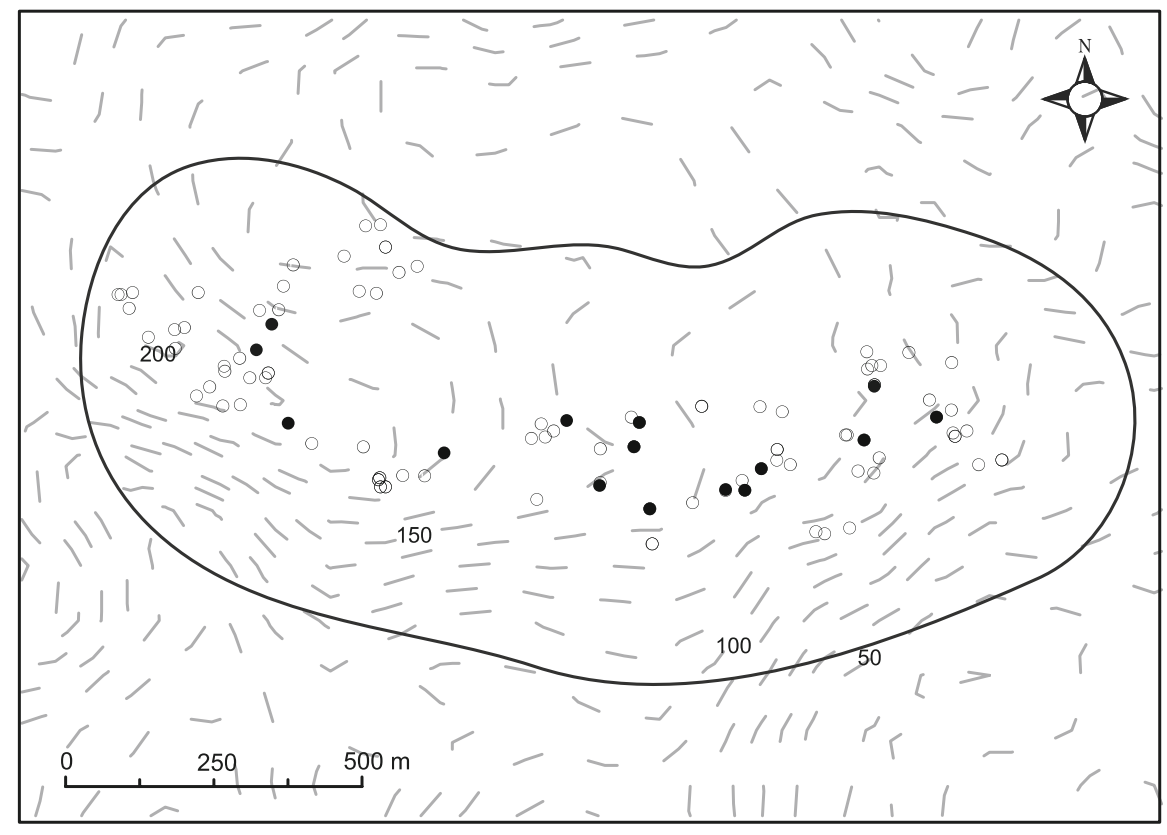

The online version of the original article can be found under doi:10.1007/s10265-009-0265-1.

\section{Y. Takeuchi $(\square)$}

Laboratory of Forest Biology, Graduate School of Agriculture, Kyoto University, Kitashirakawa Oiwakecho, Sakyo-ku,

Kyoto 606-8502, Japan

e-mail: yayoit@kais.kyoto-u.ac.jp

H. Samejima

Laboratory of Forest Ecology, Graduate School of Agriculture,

Kyoto University, Kyoto 606-8502, Japan
M. Nakagawa

Graduate School of Bioagricultural Sciences,

Nagoya University, Nagoya 464-8601, Japan

B. Diway

Botanical Research Centre, KM 20, Borneo Height Road, 93250 Kuching, Sarawak, Malaysia

T. Nakashizuka

Graduate School of Life Sciences, Tohoku University,

Tohoku 980-8578, Japan 